\title{
Attitudes towards documentary soundtracks - Between emotional immersion and critical reflection
}

\author{
Iben Have
}

MedieKultur 2010, 48, 48-60

Published by SMID | Society of Media researchers In Denmark | www.smid.dk The online version of this text can be found open access at www.mediekultur.dk

Musical experience is often related to an emotional and imaginative engagement of the listener. Discourses of journalistic documentaries relate primarily to inferential knowledge systems in which the uses of background music as a communicative device become an object of epistemological critique. By listening to different voices - primarily from four focus group interviews - the article will discuss attitudes towards musical soundtracks in documentaries, attitudes being negotiated between emotional immersion and critical reflection, with the concept of manipulation as an underlying theme. In the end, the article will argue for the need for an acoustemological approach (Feld, 1996) to study the epistemological potential of sound in audiovisual media.

\footnotetext{
There are known knowns; there are things we know we know. We also know there are known unknowns; that is to say we know there are some things we do not know. But there are also unknown unknowns; the ones we don't know we don't know. And if one looks throughout the history of our country and other free countries, it is the latter category that tends to be the difficult one. (Donald Rumsfeld, 2002)
}

This was the answer U.S. Secretary of Defense Donald Rumsfeld gave at a press conference in 2002, when he was questioned about the knowledge the U.S. Department of Defense had concerning Iraq's attempt to supply terrorists with weapons of mass destruction. In quite another context and with a focus on different kinds of invisible editing in achieving 
narrative, discursive or poetic coherence when making a documentary, Michael Chanan very briefly uses Rumsfeld's three categories of knowns and unknowns pointing at different levels of reception (Chanan, 2008, p. 124). In this article, I would like to continue with Chanan's idea of using Rumsfeld's string of words by supplying the unknown knowns; things we don't know that we know when we try to make sense of a documentary's visual and auditive expressions. The unknown knowns can be used to describe the reception of nonverbal and non-propositional communicative layers of the documentary, such as voice tone, body language, facial expressions and the background music of the soundtrack, which is the focus of this article'. Unknown knowns are a part of Anthony Giddens' concept of practical knowledge and are usually perceived and understood pre-reflectively and intuitively, drawing on bodily, emotional, cultural and social knowledge. We are all specialists when it comes to de-coding these forms, but we are usually not aware of how we do it. Compared to other kinds of musical skills, the competence we use to make meaning out of background music cannot be learned at universities or music academies (as is the practice today), but is generated from everyday experience and is to a great extent influenced by audiovisual media.

Through such an extended definition of knowledge that includes bodily, emotional, cultural and social skills and competences, the discussion of consciously reflecting and intuitively experiencing will resonate throughout this article as a fundamental and inescapable issue of the documentary genre. John Corner distinguishes between the imaginative and the inferential relationship between screened events and the viewing consciousness and relates the former to fiction and the latter to documentary (Corner, in Creeber, 2001, p. 127). Everyday musical experience (including music in audiovisual media) is typically more emotional and imaginative than mentally reflected and inferential. Still, there is a strong and long tradition for using aesthetic devices like background music in even the most "serious" and authoritative TV documentaries, which might seem like a paradox. The trouble with musical sound in documentary is that it can appear difficult to "translate" into something that can be analysed, which may give rise to the experiences of feeling manipulated. By listening to documentary directors, critics and ordinary Danish TV viewers, this article will discuss attitudes towards musical soundtracks in documentaries, attitudes being negotiated between emotional immersion and critical reflection, with the concept of manipulation as an underlying theme. This leads to a classical discussion about authenticity and critical reflection in experiencing a documentary, which is related specifically to the reception of background music. In the end, the article will briefly argue for the need for an acoustemological approach (Feld, 1996) when studying the epistemological potential of sound in audiovisual media.

\section{Listening to politicians}

In a reception study from 2007-2008, I combined a reception theory approach with a smallscale qualitative interview study which focused on two documentaries, each portraying contemporary Danish politicians' private and political “backstage" (Meyrowitz, 1985), and both of 
which had been broadcast on Danish public service television during prime time. ${ }^{2}$ The overall research focus of the study was the respondents' experience of credibility and authenticity in relation to the documentary and my special interest was their experience of and attitudes towards the use of background music. Using a qualitative interview method, the aim was not to gather the pre-reflected experience of the music (the unknown knowns). But through the respondents' conscious reflections on the music - embedded in a broader discussion about the documentary genre, credibility and authenticity - the interviews provided some insight into how they engage with it as a part of the aesthetic staging of the documentaries.

The study consists of four small focus groups (4-6 persons each), categorised by age, based on the presumption that tolerance of aesthetic devices and staging in documentaries and critical attitudes towards political and journalistic communication vary with age, but apart from this, the participants' age was not a dominant issue in the study. One group of 30-40 year olds and one group of 60-70 year olds were interviewed about the documentary Fogh bag facaden (Fogh behind the Façade, directed by Christoffer Guldbrandsen, 2003) ${ }^{3}$ and one group of 20-25 year olds and another of 50-60 year olds were interviewed about the documentary Ballets dronning (The Queen of the Ball, directed by Helle Faber, 2005). In all but one of the four groups (Fogh, 30-40 years, with only one man) there was an equal distribution of men and women and all participants were from the Danish middle class, living in the eastern part of Jutland.

After a short presentation and briefing, the respondents watched their respective programmes. The only previous information they were given about the interview was that the subject was a TV documentary about a Danish politician, which we were going to see and talk about afterwards. Thus the interest in the aesthetics and music were not mentioned. After the screening, participants were interviewed for about an hour, during which they were asked to give their general impressions of the documentary, with credibility, authenticity and aesthetic staging as main themes in the semi-structured interview guide. Thereafter, the groups re-watched 1-3 clips and were asked to pay special attention to the background music, which they were interviewed more thoroughly about afterwards. The interviews were transcribed and analysed in accordance with the research interest and the themes of the interview guides. ${ }^{4}$

The interest in attitudes towards the documentary and towards its use of music was a decisive factor in the choice of method. By using focus groups rather than individual interviews, the social negotiation of attitudes is emphasised at the expense of the individual reporting of experience. Attitudes might appear clearer when related to others' opinions in a focus group, but on the other hand different attitudes might be suppressed in the group's consensus seeking dynamics, which must be taken into account in the analysis.

Both documentaries used in the interviews were directed by journalists, but are not classical authoritative journalistic documentaries, since they mix aesthetic strategies from the observational as well as the poetic documentary genres. Fogh behind the Façade follows the Danish Prime Minister, Anders Fogh Rasmussen, when he was leader of the Euro- 
pean Council. The film centres on Fogh Rasmussen's management of a European summit in Copenhagen in 2002. The Queen of the Ball is about the controversial but very successful right-wing leader of The Danish People's Party, Pia Kjærsgaard. This film follows Kjærsgaard's official as well as private life in the weeks leading up to the Danish national election in 2005, which proved an enormous success for Kjærsgaard and her party. In Fogh behind the Façade the music is quite dominant, consisting of symphonic music from the classical-romantic repertoire (Beethoven, Rossini, Shostakovich and Tchaikovsky). Some of the musical themes are culturally coded, like the grandiose finale from Beethoven's 9th Symphony, known as the official EU hymn. Or the Tchaikovsky theme played on a celeste, an instrument that sounds like small bells, which is easily associated with Fogh's extreme obsession with his timetable and his nervous clock watching. In contrast to this, the anonymous electronic soundtrack from the Danish up-and-coming, hybrid band EPO-555 in The Queen of the Ball, neither attracts much attention to the music nor gives rise to associations to something outside the music itself, but it manages discretely to add a flow of feelings and moods to the portrait. So the kinds of music used in the two documentaries are quite different and are integrated very differently in the narratives (for a more elaborate description of the music in the two documentaries, see Have, 2008a, 2008c). The overall duration of the music in The Queen of the Ball is twice as long as in Fogh behind the Façade (respectively $40 \%$ and $20 \%$ of the programmes' duration). However, the focus group interviews indicated that it is not the quantity of music that makes it audible. In the Fogh behind the Façade interviews, only one respondent out of ten did not pay some kind of reflected attention to the music during the screening and participants in the older group reflected upon it and talked about it very early in the interview. In The Queen of the Ball interviews, only one respondent out of eight noticed the music before they were asked to pay special attention to it in relation to the replayed clips. This difference can be explained by the different communicative appeal and perceptual affordance of the different kinds of music used in the two documentaries.

In general, the reception study supports the observation made by John Corner (Corner in Creeber, 2001) that documentaries relate much more directly to inferential knowledge than to imaginative and emotional experience. In contrast to fiction, documentary aesthetics are not evaluated as positive creativity (Corner, 2008, p. 21). Instead, the use of aesthetic devices like background music becomes the object of epistemological critique and is evaluated as a negative creativity, as emotional seduction and perhaps even deception. In the following, I will focus on the respondents' conflicts between the two knowledge systems (the inferential and the emotional) when reflecting on the role of the music. The experience of manipulation seems to be a significant factor in descriptions of that experience.

With regard to the respondents' attitudes towards using music in documentaries, the dominant position is that background music manipulates (or "colours reality" as some of them critically said) and therefore in principle should not be used in documentaries like this. Only the 20-25 year-old group members were not critical of the use of music, and adopted the following type of attitude instead. 
The music is just generating a mood or an emotion in people. It is extremely important in this kind of documentary. It is used to try to create some sympathy. (The Queen of the Ball, male $20-25$ years $)^{5}$

In one of the groups (Fogh, older), the use of music gives rise to descriptions like propaganda and manipulation very early in the interview.

But it had a touch of a propaganda film of a kind. I know that it isn't, but the music [short pause] it begins with that ... (humming the Finale of Beethoven's $9^{\text {th }}$ ). (Fogh behind the Façade, male 60-70 years)

The whole interview situation and being in a group of strangers, as well as the topics discussed, undoubtedly amplified the urge to present oneself as a critical media consumer. But the attitudes of the critical groups however do change during the interviews. The more reflected they are (or become) of the music (whether they consciously noticed it from the beginning or only when they were asked to listen to the clips), the less manipulating in the negative sense of the word the music seems to be for them. When they hear and consciously reflect upon the role of the music, they seem more capable of deciding what kind of emotional and ideological messages to accept and which to reject. This change from a rejecting to a more accepting attitude towards the use of music is most noticeable in the older group watching The Queen of the Ball. Here are two quotes from one man:

No, it is not all right. It never is in a documentary. In a fiction film it is all right that the music manipulates us, because it must provoke some feelings. That is all it does. In a documentary it is obviously not right. It is sad that we do not notice. (The Queen of the Ball, male 50-60 years)

But later in the interview this man says:

They manipulate and use effects to make us experience her state of mind. They do not manipulate to make us change our mind about her. So in that way it is quite harmless [short pause] but it is not nice to find out that you have been manipulated without noticing it. (The Queen of the Ball, male 50-60 years)

Most of the respondents in this group however remain cautious, and maintain the feeling that someone is trying to make them believe something against their will.

I am thinking about [short pause], there is something inside me saying that it is a sympathetic person we are dealing with here. But I do not think she is. For me it is weird. I feel confused, because there is a signal, and it might be the music signalling something other than the attitude I usually have towards this person. [Later in the interview] I think something in the film touched me, but I do not want to be touched, because I want to maintain my pre-determined opinion about how she is. (The Queen of the Ball, female 50-60 years) 
This citation clearly illustrates how the respondent's emotional experience is in conflict with her rational opinion of the politician, which leads to confusion. In general there is consensus on music generating moods and emotions, and the two groups watching The Queen of the Ball both agree about experiencing it as a sympathetic portrait. But as you can see from the quotes, there are differences as to whether the respondents think this is a problem or not. Some see it as a necessary device (primarily the youngest group), others oppose the presence of the music (primarily the two older groups).

The interviews suggest that age and, but not least (and not surprisingly), the respondents' pre-opinion of the politicians are factors in the degree of their critical attitudes towards the documentaries and media-representations of politicians in general, which corresponds with research on audio-visual advertising and persuasion.

Persuasion research has shown that if a viewer has a stable attitude about something, no music, be it popular or "emotionalizing", can change it. Music and other peripheral cues are much more effective at bringing about attitude change when attitudes are lightly held and labile. (Bullerjahn, 2006, p. 225)

Certainly Danish politicians, and definitely the controversial ones like Kjærsgaard, are individuals that Danish viewers have strong opinions about, as opposed to an advertisement's launching of a new shampoo or car, where the background music may influence their attitudes to a greater degree.

A study such as the one under discussion may throw light on some peoples' attitudes towards the use of music in documentaries, but as mentioned earlier it provides little information about how they perceive and generate meaning from the music while watching the documentary. Experimental psychological tests on audiovisual perception measure the direct arousal and effect on the audience and may bring us closer to understanding people's perceptions of background music (Annabel ). Cohen's studies being the most significant; see also Bullerjahn, 2006; Tsang, 2007; and Graakjær, 2008, for a review of other experimental tests studying the perception of music in an audiovisual context), but these studies cannot stand alone either, isolated as they often are around an artificial and text-based set-up, reducing or neglecting the physical, cultural and social context of the natural reception situation.

In the current study, the respondents found it very hard to talk about their experience of the specific musical meaning in relation to the replayed clips. In the Fogh behind the Façade groups, I asked the respondents to write down their associations when they listened to a clip using Shostakovich's Jazz-suite 2, "Waltz No. 2", while Fogh Rasmussen is shown leaving his office dressed ready to meet the Polish Prime Minister. In the first part of the scene, the camera follows him from behind and later in the scene we see him unsuccessfully waiting for an elevator. The associated feelings and interpretations of mood reported by the respondents when listening to this scene ranged from "easy", "soft", "hesitant", "sad", and "lonely", to "powerfulness" and "Godfather-like", and there were some who described the music as 
conjuring up the idea of a "circus", "ice-dancing" and "a dance ball in the castle". Many of these associations seem to emerge from bodily as well as cultural knowledge related to the slow waltzing $3 / 4$ time and the soft brass instruments. Furthermore, the visuals seem to influence descriptions like loneliness, powerfulness and Godfather-like.

Professor of musicology Philip Tagg conducted a systematic investigation of peoples' experience of the musical meaning, which the current study only briefly addresses. Between 1979-1985 he asked more than 600 respondents to write down their verbal and visual associations (VVAs) while listening to ten title themes used in film and television. His method was strictly semiotic and the results are published in the 900-page long book Ten Little Title Tunes (2003). Tagg's method is primarily quantitatively reminiscent of a survey and systematically based on a micro-musical level, studying the particular significations of a single musical figure or a musical sound, without taking the medium into account. In comparison, the current study did not focus on collecting the specific musical meaning of the respondents, but through qualitative interviews created a dialogue among the respondents about their attitudes towards the use (and as a part of that the meaning) of the background music. A fundamental problem with Tagg's method was that he removed the visuals while the respondents listened to the tunes. Thus, his results tell us something about the associated meaning of music, but do not say much about the audiovisual experience of music. I tried to avoid that by aiming at a natural reception situation, and letting the respondents talk about the music as a part of an audiovisual whole in a specific medium and a specific genre.

Due to the ubiquitous phenomenon of background music, no empirical method seems yet to be able to fully describe the intuitive experience of music as a communicative device in audiovisual media. A problem for experimental, semiotic as well as qualitative interview studies is that the spoken word is often a necessary but not always the most adequate tool for description. ${ }^{6}$

\section{Reflection or immersed authenticity}

Corresponding to Corner's division of imaginative and inferential modes of engagement with screened events, Annette Hill, in her recent empirical study on documentary modes of reception, addresses the issue of the two similar modes, although both are related to documentary. Hill concludes in her study that: "Viewers are both immersed in a documentary and reflective of it, ensuring multiple modes of engagements with documentary and its wider role in society and culture" (Hill, 2008, p. 229). My own reception study indicates the same management of different modes of engagement, also when it comes to the music, which is not just perceived in an imaginative and immersing manner, but also can cause reflection at the moment of reception and can be remembered after a screening - even though the respondents find the specific meaning hard to describe.

This distinction between immersion and reflection (see also Munday, 2007, for this pair of concepts in relation to background music in video games) also represents two voices 
in the general debate about the role of background music in documentaries - a debate I have some understanding of, having had my attention directed towards it in the Danish media and in academia for almost a decade. One of the voices typically comes from the producers (here referring to people involved in the production of the documentary) and the other from the critics (scholars or public debaters), who typically have some kind of concern about the manipulating forces of music. People related to the production, such as the editor cited below, on the other hand, usually defend the use of music with the argument that they use music to make the documentary more authentic, more real.?

\begin{abstract}
In Vores lykkes fjender [The enemies of our happiness, a Danish prize winning documentary from 2006], the main character was constantly in mortal danger, but it was difficult to tell through the visuals alone. She lived on one side of the road and worked on the other side, and to let her cross the road they had to close the whole road. The visuals show some guards standing. It did not look very dangerous. So we had to help increase the understanding of the situation a little bit. But how do you show something you cannot see? Here music can be a good tool. Some might say that is manipulation, but then all in a documentary is manipulation: framing, cutting etc. So why draw a line with music? Rather than being true to some kind of abstract ideal, I would rather try to recreate the feeling of the reality, which the director had when she was in the situation. (Adam Nielsen, editor, in Movin, 2007, p. 2, translated from Danish)
\end{abstract}

The director of The Queen of the Ball shares this opinion and in an interview she said that she uses the music to communicate "the inside" of the politician, Pia Kjærsgaard, meaning her state of mind and feelings.

To give her [Kjærsgaard] some depth - to give her some emotional layers, which we do not experience from the news - I decided that I would work more with sound. Try to create moods and emotions that I imagined were inside of her. (Helle Faber, 2007, translated from Danish)

The director of Fogh behind the facade, Christoffer Guldbrandsen, has commented on his use of music in his documentaries in general.

It is evident, that when you make a documentary film, you do it because you want to communicate some information, a story and sometimes even a kind of artistic idea. It is about translating politics and law into emotions and that is why we use music and pictures. (Christoffer Guldbrandsen, from the radio programme Mennesker og medier, P1, December $8^{\text {th }} 2006$, translated from Danish)

The quotes above all have a strong focus on music's and sound's ability to create an emotional experience as an important part of communicating through the documentary genre.

The critical voice in the debate is, among others, represented by Philip Tagg. In his article "Music, moving image, semiotics and the democratic right to know" (2006), he argues that 
the feeling of being manipulated by background music only in rare instances emanates from a hidden agenda of the director, but is more likely to come from the perceiver's conflict between being confident with the emotional reaction to music, but on the other hand not confident reflecting that reaction (there are things we don't know that we know). Therefore the feeling of manipulation is not a result of a hidden agenda of the producer to which we as recipients are passively exposed, but a feeling we can actively "neutralise" by gaining more knowledge about what makes us react as we do - being able to make the unknown (consciously) known, removing it from practical to discursive knowledge.

\begin{abstract}
Music may be just as important as words or pictures in communicating how we should value, despise, admire, fear, love or hate other people or ourselves, other cultures or our own. The only difference is that while education may help us, if we are lucky, to reflect upon and criticise messages that come to us through visual and verbal media, we are not trained to reflect upon or criticise musically mediated ideology. We are in this sense more open to manipulation through music than through most other channels of mediating meaning. (Tagg, 2006, p. 169)
\end{abstract}

A similar (but less critical) approach is taken by Ulrik Volgsten:

Music's strength as an ideological expression - its manipulative force par excellence comes from the capacity of musical sounds to affectively articulate the verbal discourses to which they become indissolubly tied. Affect is what makes music's ideological dimension both subtle and powerful. (Volgsten, 2006, p. 77)

From this perspective (Tagg's more than Volgsten's), the more reflected, the more explicit the implicit musical knowledge gets, the less manipulated we are. Therefore you might say that the music of Fogh behind the Façade seems to be less manipulating than the music of The Queen of the Ball, since the viewers of the first documentary consciously took notice of the music and reflected upon its presence very early during the screening. The reflectionclaiming critical voice is not consistent with the voice of the producers', since the reflective mode of engagement prevents an immersed experience of authenticity. Thus, the two modes of musical engagement cannot exist simultaneously, but as recipients we easily alternate between them while watching a documentary.

But the critical perspective still takes for granted that there is some kind of "uncoloured" reality behind the audiovisual presentation that we should strive for; that it is possible to reach a point where we are not manipulated. But does such a point exist? Music as a communicative device is meant to have some kind of effect on the listener. Emotions and moods are an essential part of this effect. When emotional experience stays un-reflected, we talk about manipulation and seduction. In contrast, words like persuasion and conviction are related to rational and logical communication. All four concepts imply an activity, where the receivers' attitudes or behaviours are to some degree changed. But manipulation 
and seduction imply some kind of (preceding) resistance of the receiver (the one being seduced or manipulated). If the critical TV viewer begins to listen instead of being automatically resistant to the use of music in documentaries, the feeling of manipulation may to some degree turn into conviction and, like the respondents in the reception study, make the viewer able to make his or her own decisions about what kind of emotional and ideological messages to accept and which to reject.

In the article "Sounds Real", John Corner (2005) argues that on a continuum from "serious" to "light" documentary, we seem to be more critical of the use of background music the more serious the documentary appears. That means that we usually have a critical attitude to the music in serious (journalistic) documentary, whereas in "lighter" and entertaining formats like reality TV, music is used more frequently and is more widely accepted. Corner himself argues that this observation symbolises a "strong tendency" in practice (Corner, 2005, p. 247f), but it still needs to be empirically tested. Moving this serious-light axis from the documentary genre to television channels in general (and adding "commercial" to the light end of the axis), a preliminary study, conducted on a randomly chosen Thursday evening between 20:00 and 22:00 in 2004, may to some extent empirically confirm this tendency. The study showed that there was non-diegetic music (jingles and background music) about $40 \%$ of the time on average, on all eight Danish television channels available at the time. The numbers in figure 1 indicate that the amount of music (in most of the cases) is linked to the general and common conception of the stations' autonomy and degree of commercialisation: for example, the "intellectual" public service channel DR 2 used music during $22 \%$ of the two hours, the broad public service channel DR 1 for $40 \%$ of the time, and the commercial channel TV 3 for $63 \%$ of the time (see figure 1). Not all the numbers however fit the general view. For example TV 2 Zulu is usually considered to be more popular and commercial than is DR $1 .{ }^{8}$

Amount of background music and/or jingles

DK 4 (8\%); DR 2 (22\%); TV 2 Zulu (26\%); DR 1 (40\%); TV 5 (53\%); TV 2 and TV $3+(56 \%) ; \operatorname{TV} 3$ (63\%)

Figure 1: A sample of the quantity of music on Danish TV channels measured on a randomly selected Thursday night between 20:00 and 22:00 in 2004. The model uses the graphical indication from musical scores, signalling the sound growing louder and louder - a crescendo - as a metaphorical indication of the increasing quantity (not volume) of music.

Due to a mistake made by the student group responsible for timing the music on channel TV 2 Zulu, they measured the music the day after, the $10^{\text {th }}$ of September 2004, but during the same period of time: 20:00 to 22:00. 
Despite the minor deviations, this study indicates how the quantitative use of music in audiovisual practice on different Danish TV channels on a general level reflects a common understanding of music as being related to the less serious (popular, commercial) programming at the light end of the continuum axis as defined by Corner - an understanding confirmed in the focus group reception study as well.

\section{Towards an audiovisual acoustemology}

The question of manipulation and the discussion of different kinds of knowledge systems unfold within a broader acoustemological field about how reality, knowledge and emotions are realised, mediated and experienced through sound in audiovisual media in general. Following music ethnologist Steven Feld, acoustemology is a theory of the epistemological potential of sound and audibility:

Acoustemology, acousteme: I am adding to the vocabulary of sensorial-sonic studies to argue the potential of acoustic knowing, of sounding as a condition of and for knowing, of sonic presence and awareness as potent shaping forces in how people make sense of experiences. (Feld, 1996, p. 97)

A main acoustemological question, constituting a frame for all acoustemological research, is what can we know - meaning, what kind of knowledge, identity, values and communication are possible - through auditive practice and auditive representation? Since we live in an audiovisual media culture (not only in a visual culture, which has been claimed in humanities for decades), I find it important to approach the epistemological potential of sound and music within audiovisual media - asking what can we know (and, considering the present cases of this article, what do we like to know) from musical sound in audiovisual media and audiovisual genres? The answers to these questions can only be discussed situated and contextualised, which I have tried to do here by focusing on a particular genre and some particular cases. With an acoustemological approach to audiovisual media, two broader questions need to be investigated, which I have only briefly touched on here. First, what role does sound and music play in understanding, knowing and experiencing audiovisual media content? And second, what effect do different media (technological, social and cultural) and genres have on auditive realisation and experience?

Turning from a research perspective to a recipient perspective, the reception study suggests that imaginative and inferential, emotional and critical modes of engagements interact when we watch a documentary, and by recognising the unknown knowns we will be able to overcome the widespread automatic reaction that background music is manipulating, and instead begin to listen to what the music communicates. But to grasp this everyday experience of the musical meaning is still a great challenge for acoustemological research. 


\section{References}

Bondebjerg, I. (2008). Virkeligheden fortellinger. Copenhagen: Forlaget Samfundslitteratur.

Bullerjahn, C. (2006). The effectiveness of music in television commercials. In S. Brown \& U. Volgsten (Eds.), Music and manipulation: On the social uses and social control of music (pp. 207-235). New York \& Oxford: Berghahn Books.

Chanan, M. (2008). Filming the "Invisible". In T. Austin \& W. de Jong (Eds.), Rethinking documentary: New perspectives, new practices (pp. 121-132). Berkshire: Open University Press McGraw-Hill Education.

Cook, N. (1998). Analysing musical multimedia. Oxford: Clarendon Press.

Corner, J. (2005). Sounds real: Music and documentary. In A. Rosenthal \& J. Corner (Eds.), New challenges for documentary (pp. 242-252). Manchester \& New York: Manchester University Press.

Corner, J. (2008). Documentary studies: Dimensions of transition and continuity. In T. Austin \& W. de Jong (Eds.), Rethinking Documentary: New Perspectives, New Practices (pp. 13-28). Berkshire: Open University Press McGraw-Hill Education.

Creeber, G. (Ed.) (2001). The television genre book. London: British Film Institute.

Damasio, A.R. (2000). The feeling of what happens: Body, emotion and the making of consciousness. London: Vintage.

Faber, H. (2007). Interview, Bastard Film, Copenhagen, November the $5^{\text {th }}$. Faber was interviewed by four students from Media Studies, Aarhus University.

Feld, S. (1996). Waterfalls of song: An acoustemology of place resounding in Bosavi, Papua New Guinea. In S. Feld \& K.H. Basso (Eds.), Senses of place (pp. 91-135). Santa Fe: School of American Research Press.

Graakjær, N. J. (2008). Musik i tv-reklamer: En tekstanalytisk undersøgelse. Ph.D. dissertation, Aalborg University.

Have, I. (2008a). Background music and background feelings: Background music in audio-visual media. Journal of Music and Meaning no 6. www.musicandmeaning.net.

Have, I. (2008b). Lyt til tv: Underlagningsmusik i danske tv-dokumentarer. Aarhus: Aarhus University Press.

Have, I. (2008c). Manipulerer underlagningsmusik?: Spørgsmål om troværdighed og iscenesattelse i receptionen af dokumentar-tv, working paper. www.high-tension-aesthetics.com.

Have, I. (2009). Underlægningsmusik i dokumentariske politikerportrætter. In A. Jerslev \& C.L. Christensen (Eds.), Hvor går graensen?: Brudflader i den moderne mediekultur (pp. 177-202). Copenhagen: Tiderne Skifter.

Hill, A. (2008). Documentary modes of engagement. In T. Austin \& W. de Jong (Eds.), Rethinking documentary: New perspectives, new practices (pp. 217-231). Berkshire: Open University Press McGraw-Hill Education.

Meinertsen, P. (2006). Lydens rolle: Notater om lyd os musik til film. Copenhagen: Den Danske Filmskole.

Meyrowitz, J. (1985). No sense of place: The impact of electronic media on social behavior. New York, Oxford: Oxford University Press.

Movin, L. (2007). Rum til refleksion. Film No. 56, April 2007. http://www.dfi.dk/tidsskriftetfilm/56/lyd2.htm.

Munday, R. (2007). Music in video games. In J. Sexton (Ed.), Music, sound and multimedia (pp. 51 64). Edinburgh: Edinburgh University Press.

Rumsfeld, D. (2002). News briefing, February 12, US Department of Defense. http://www.defenselink.mil/ transcripts/transcript.aspx?transcriptid=2636.

Tagg, P. (2006). Music, moving image, semiotics and the democratic right to know. In S. Brown \& U. Volgsten (Eds.), Music and manipulation: On the social uses and social control of music (163-186). New York \& Oxford: Berghahn Books.

Tagg, P., \& Clarida, J. (2003). Ten little title tunes. New York \& Montreal: The Mass Media Music Scholars' Press. 
Tsang, L. (2007). Sound and music in website design. In J. Sexton (Ed.), Music, sound and multimedia (pp.145171). Edinburgh: Edinburgh University Press.

Volgsten, U. (2006). Between ideology and identity: Media, discourse and affect. In S. Brown \& U. Volgsten (Eds.), Music and Manipulation: On the social uses and social control of music. New York \& Oxford: Berghahn Books.

\section{Notes}

1. In the remainder of this article, "background music" refers to music applied in the editing process as a part of the soundtrack.

2. The study was a part of the research project High-tension Aesthetics. Ethics and Aesthetics in Contemporary Media (2005-2008), financed by the National Research Council for the Humanities, http://www. high-tension-aesthetics.com/home_uk.htm. Some of the issues presented in this article have previously been published in Danish (cf. Have, 2008a, 2009).

3. The official English title of this documentary is The Road to Europe, but I use a Danish translation Fogh behind the Facade, which refers to the politician portrayed (Anders Fogh Rasmussen).

4. The first two interviews I designed and conducted myself. The other two were conducted by a group of students I instructed in relation to a course I ran in Media Studies, Aarhus University, 2007. There were a few variations between the way in which the students and I conducted the work - for example the ages of the groups are not identical. But in general the overall design is close. The students allowed me to use the transcriptions from their interviews in my own research. For further details concerning the methodological design of the study, see Have, 2008c.

5. All the quotes from the interviews are my own translations from Danish and the original spoken utterances are modified to written language.

6. To overcome the problem with language in describing musical experience, Morris and Boone (1998) created a visual "Self-Assessment Manikin" (15 different drawings of a simple cartoon character), as a non-verbal means of describing feeling states in relation to music applied to 12 printed advertisements (Bullerjahn, 2006, p. 219).

7. Sound director and teacher at the Danish Film Institute Per Meinertsen is here an exception. In his book Lydens rolle: Notater om lyd os musik til film (2006), he presents a critical attitude towards the use of music in documentaries.

8. The numbers are from a pilot study conducted as part of a course that I conducted in Musicology at Aarhus University. The students were divided into eight groups, each responsible for the registration of the amount of non-diegetic music on a single TV channel measured in minutes and seconds with a timer.

Iben Have

Associate Professor, Ph.D.

Department of Information and Media Studies

Aarhus University, Denmark musih@hum.au.dk 